\title{
INFANTILISM IN PITUITARY DISEASE *
}

\author{
ALBION WALTER HEWLETT, M.D. \\ ANN ARBOR, MICH.
}

Since the appearance of Fröhlich's paper ${ }^{1}$ in 1901, it has become generally recognized that tumors in or near the pituitary gland may cause disturbances of body growth and general metabolism which are quite distinct from acromegaly and gigantism. Frankl-Hochwart ${ }^{2}$ has recently collected and analyzed the findings in 155 pituitary affections of this character. The symptoms present may be roughly divided into two classes: those due to the mechanical effects of the tumor and those which seem to be due to an altered internal secretion. 'To the former group belong the headache, vomiting and visual disturbances. The most characteristic of these, primary optic atrophy and unilateral or bilateral temporal hemianopsia, are due to direct pressure on the optic chiasm or nerves. To the latter group belong the sexual disturbances (retarded sexual development, cessation of menses, etc.), the obesity, the stunted growth, and possibly the occasional diabetes insipidus. These are due, in part at least, to a diminished secretion of the anterior lobe of the gland (hypopituitarism).$^{\mathrm{s}}$

\section{REPORT OF CASES}

Owing to the general interest in this group of conditions and to the fact that they are probably more common than is generally supposed, it seems advisable to report the following case histories, even though the diagnoses were not confirmed at autopsy or operation. The clinical pictures presented by the first two patients are so characteristic as to leave little doubt concerning the nature of the trouble. The third, a doubtful case, is reported because the effect of lesser changes in the pituitary secretion is but little understood and because it is probable that in this patient we are dealing with a mild form of chronic hypopituitarism.

CASE 1.-History of brain tumor. Blindness due to primary optic atrophy. Retarded growth. Sexual infantilism. Obesity. Diabetes insipidus.

* From the Department of Internal Medicine, University of Michigan.

* Read in the Section on Practice of Medicine of the American Medical Association, at the Sixty-Second Annual Session, held at Los Angeles, June, 1911.

1. Fröhlich, Alfred: Ein Fall von Tumor der Hypophysis cerebri ohne Akromegalie, Wien. klin. Rundschau, 1901, xv, 883, 906.

2. Frankl-Hochwart, L., v.: Die Diagnostik der Hypophysistumoren ohne Akromegalia, Wien. med. Wchnschr., 1909, lix, 2127, 2258, 2326.

3. Cushing, H.: Partial Hypophysectomy for Acromegaly, Am. Surg., 1909, cl, 1002; Biedl, A.: Innere Sekretion, Berlin and Wien, 1910. 
History.-The patient was a young man, aged about 27; family history negative. Between the ages of 5 and 9 years he had the typical symptoms of brain tumor, with severe headaches, vomiting, marked emaciation, and gradually developing dimness of vision which progressed to complete blindness. At this time also he began to suffer from polyuria. At about the age of 9 the headaches and vomiting disappeared, the patient began to increase in weight, and since that time he has been excessively fat. He has never shown the slightest indications of sexual development.

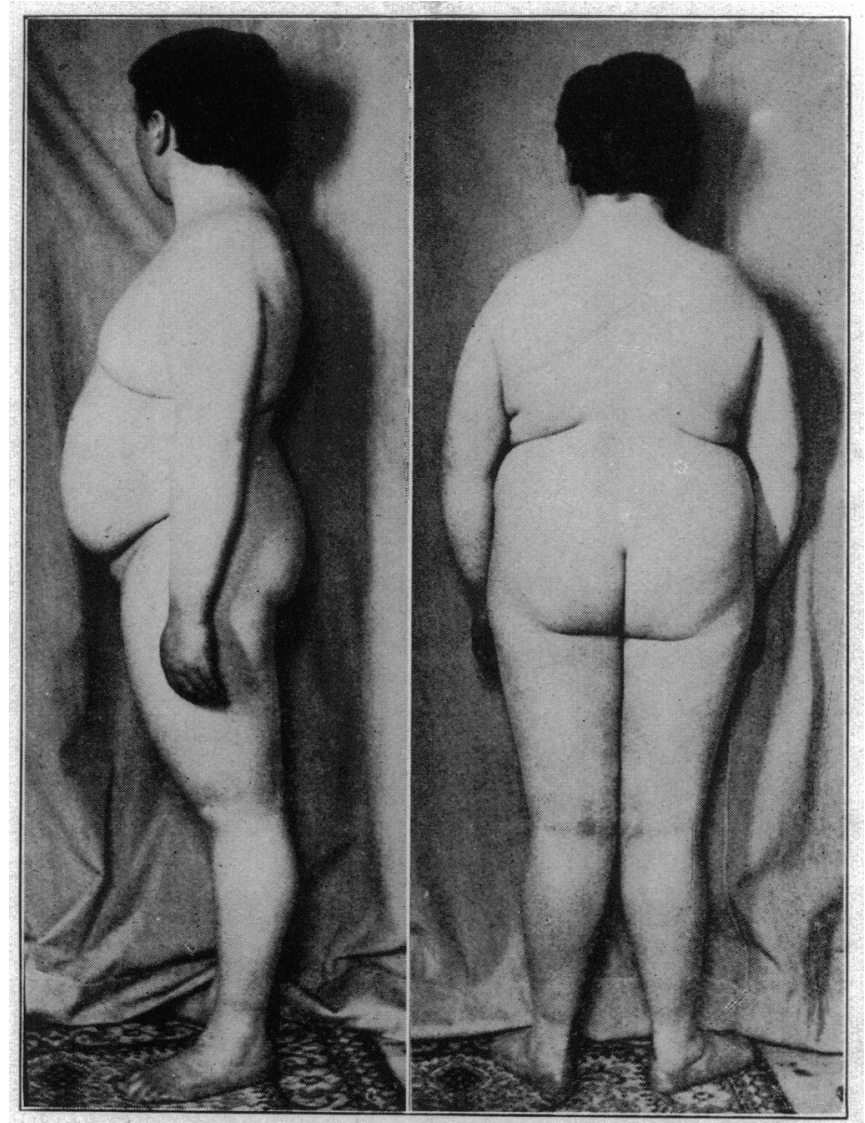

Fig. 1.-Lateral view of patient 1. Note the obesity, lumbar lordosis, small hands and feet.

Fig. 2.-Posterior view of patient 1. Notice the genu valgum and the distribution of fat on the body.

Examination.-The patient presented the general appearance of a blind, fat boy (Fig. 1); height in stocking-feet 4 ft. $9^{1 / 2}$ in.; head fairly large; supraorbital ridges not well developed; lower jaw rather small. The teeth were crowded together on both jaws. No marked disproportion existed between the length of the body and that of the extremities. There was marked genu valgum (Fig. 2). The hands were small and chubby, with delicate tapering fingers (Fig. 4). The feet were also very small and there was flat-foot on both sides.

The fat over the whole body was increased, the weight being $1661 / 2$ pounds. Deposits of fat were especially marked in the mammx, buttocks, abdomen. 
and above the symphysis pubis (Figs. $1,2,3$ ). These gave the figure a feminine appearance. The penis was very small and almost covered by the mass of fat about the mons veneris. The scrotum was small and buried in fat. Botls testicles were of infantile type, the left being descended normally, the right felt at the external ring.

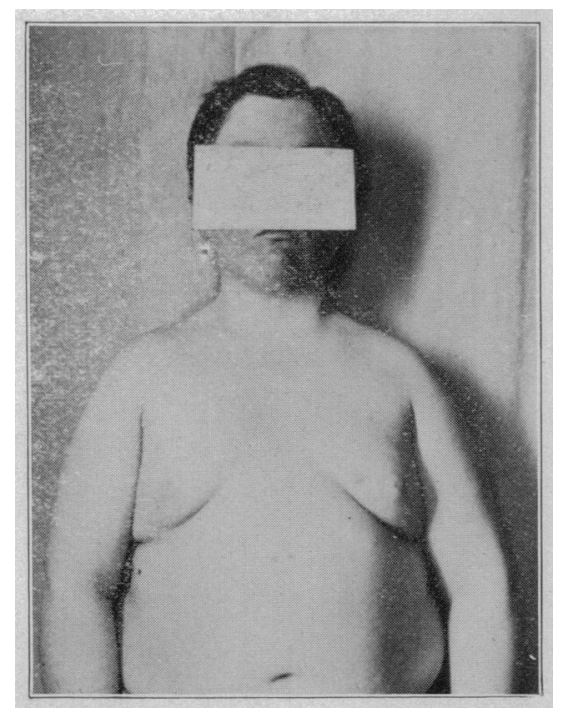

Fig. 3.-Anterior view of patient 1. Notice the distribution of fat.

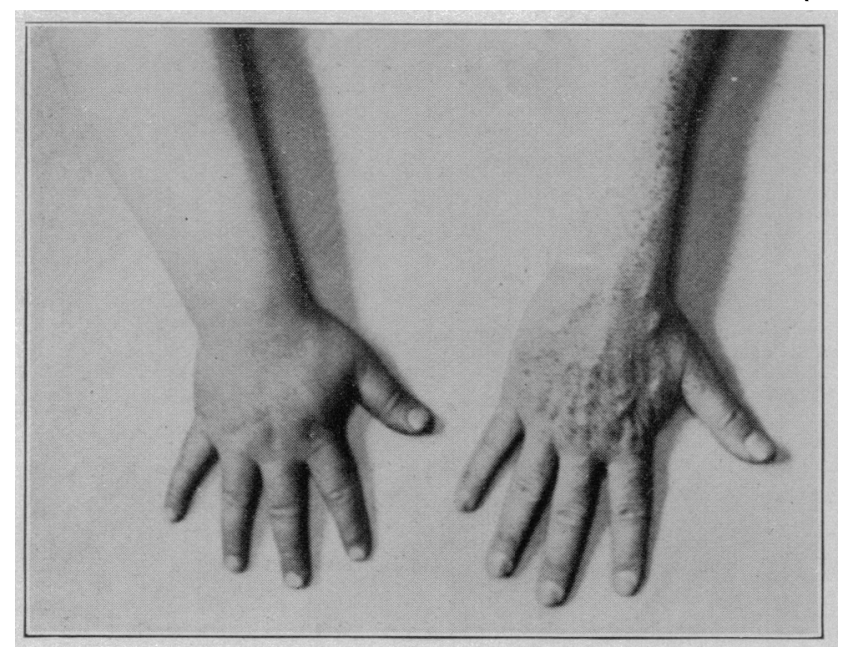

Fig. 4.-Hand of patient 1 (to the left).-Compared with hand taking a No. 7 glove. Note the small size, the tapering fingers and the delicate skin.

The hair over the head was normal; over the body, it was very fine and soft. No beard had ever developed and only a few coarse hairs were present in the axillæ and about the pubes. The skin was soft and delicate. The voice was high-pitched and of a melodious quality. The patient presented many emotional 


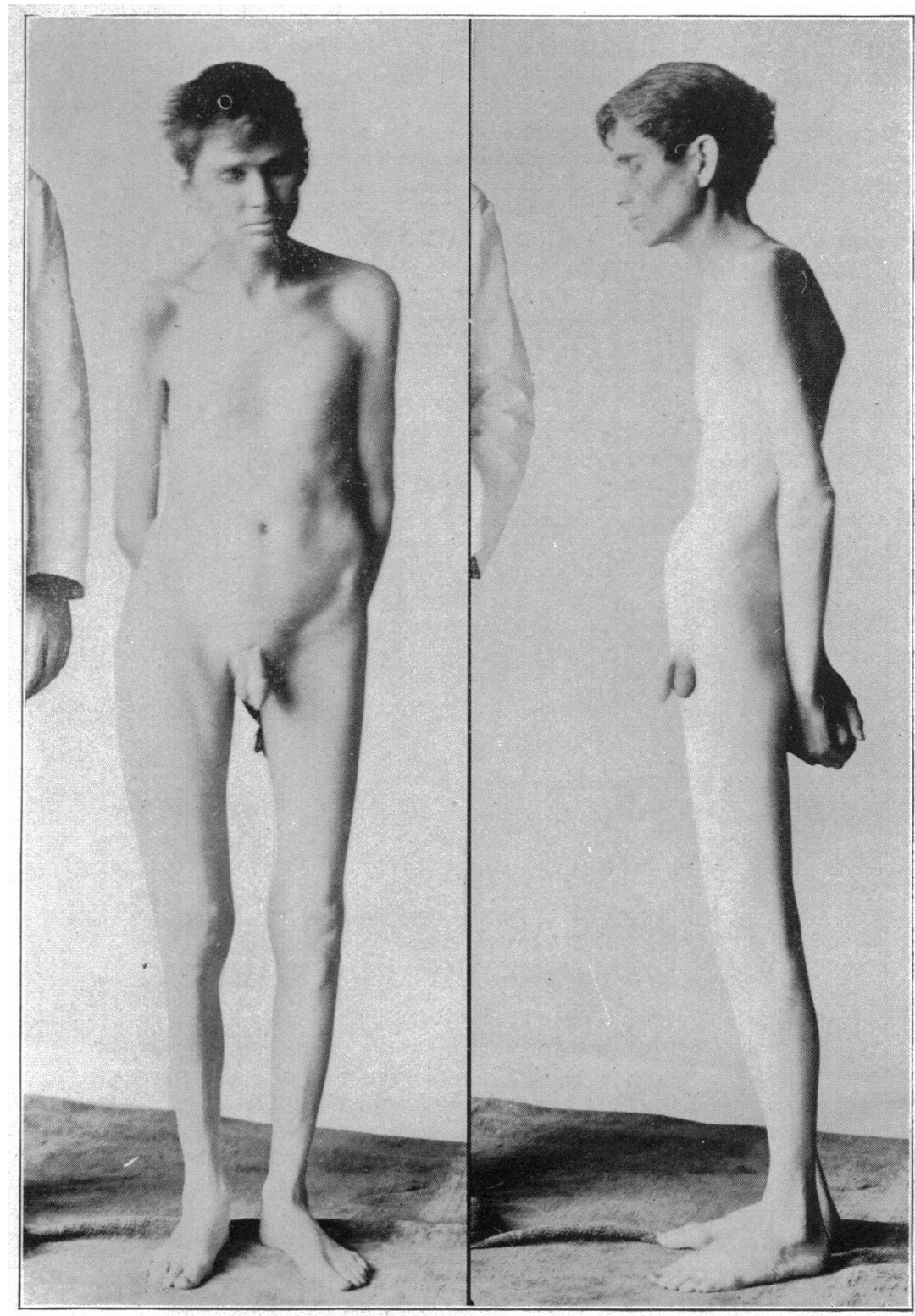

Fig. 5.-Anterior view of patient, Case 2, by the side of a man 5 feet 8 inches high. Note the adolescent figure and the absence of hair on the face and pubic region.

Fig. 6.-Patient 2, lateral view. 
characteristics of childhood, being affectionate, buoyant, but inclined at times to discouragement and weeping spells. His general intelligence and intellectual development were good, and, in spite of his blindness, he was able to manage a small business very successfully.

Since childhood the urine had always been increased in amount; at times, according to the patient's statements, reaching eight or more quarts a day. Repeated examinations of the urine showed a specific gravity which did not vary from 1,003 to 1,004 . The urinary examinations were otherwise negative.

The eyes were completely blind. An examination showed: "Both pupils slightly dilated, the left one more than the right. Neither react to light, the light perception being nil. Some nystagmus is present, probably due to inability to fix objects. Extrinsic eye-muscles normal. Ophthalmologic examination shows clear media. The fundus is somewhat over-pigmented, but probably not pathologically so. Both nerve-heads show elear margins and are bluish-white in color. The objective picture is that commonly seen in primary optic atrophy. The vessels show no evidence of pressure."

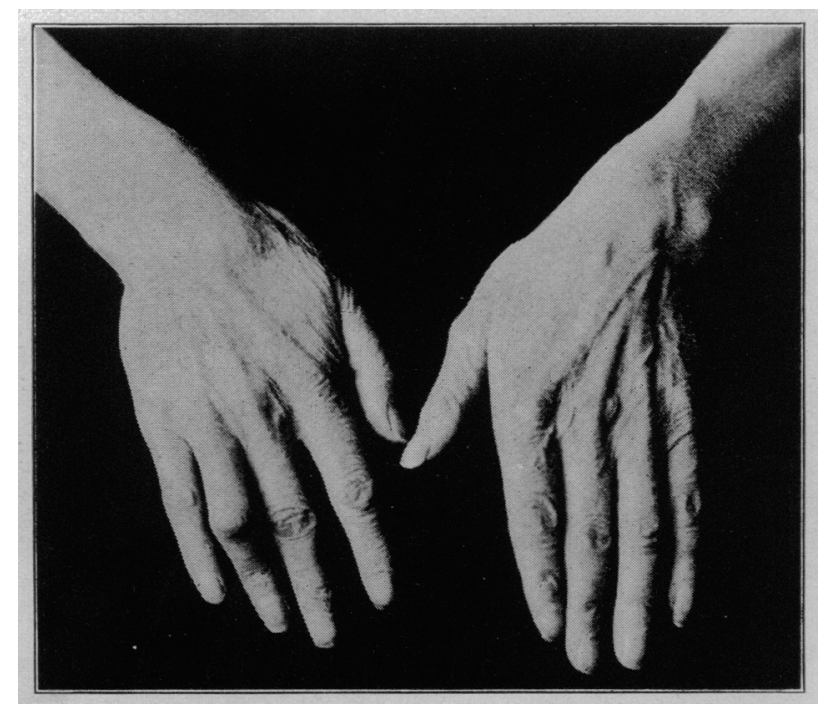

Fig. 7.--Hands of patient, Case 2. Note the long slender fingers and dry skin.

Two attempts were made to obtain radiographs of the skull but the plates were not good. As the patient complained of headache after having been exposed to the $x$-ray, no further efforts in this direction were made. Plates of the hands showed complete fusion of the metacarpal and phalangeal epiphyses. The lower epiphyses of the ulnar and radius were also fused but the lines of fusion were plainly visible and were indicated by notches on the edges of the radii so that the fusion was probably recent and considerably delayed beyond the normal."

The history of brain tumor, the stunted growth, optic atrophy, obesity, sexual infantilism and diabetes insipidus leave no doubt as to the presence of a tumor in or near the pituitary gland producing symptoms recently attributed to hypopituitarism. The patient took the powdered

4. Rotch, T. M., and Smith, H. W.: A Study of the Development of the Epiphyses of the Hand and Wrist for the Purpose of Classifying the Cadets at Annapolis, Tr. Assn. Am. Phys., 1910, xxv, 200. 
anterior lobe of the hypophysis, $15 \mathrm{gr}$. (1 gm.) a day, for over a month but without marked effect. More recently he has been given the powdered thyroid glands, but after about two weeks he complained of pains in the head, dizziness and apprehensive sensations which led to a discontinuance of the medication.

CASE 2.-Since the age of 13, periodic headaches with vomiting. Mild sexual infantilism. Adolescent height and figure. Bitemporal hemianopsia, with primary optic atrophy. Bony changes in the region of the sella turcica.

History.-A man, aged 40, first entered the University Hospital at Ann Arbor, July 7, 1910, complaining of dimness of vision, constipation, palpitation of the heart and general weakness. His family history was negative, except that one sister was suflering from a nervous trouble. Patient had had the ordinary diseases of childhood. He denied venereal infection. As a child he had gone to school and had had no difficulty in keeping up with his classes. At about the age of 13 he began to suffer from periodic headaches which were usually associated with vomiting, coming on one or two hours after the onset of the
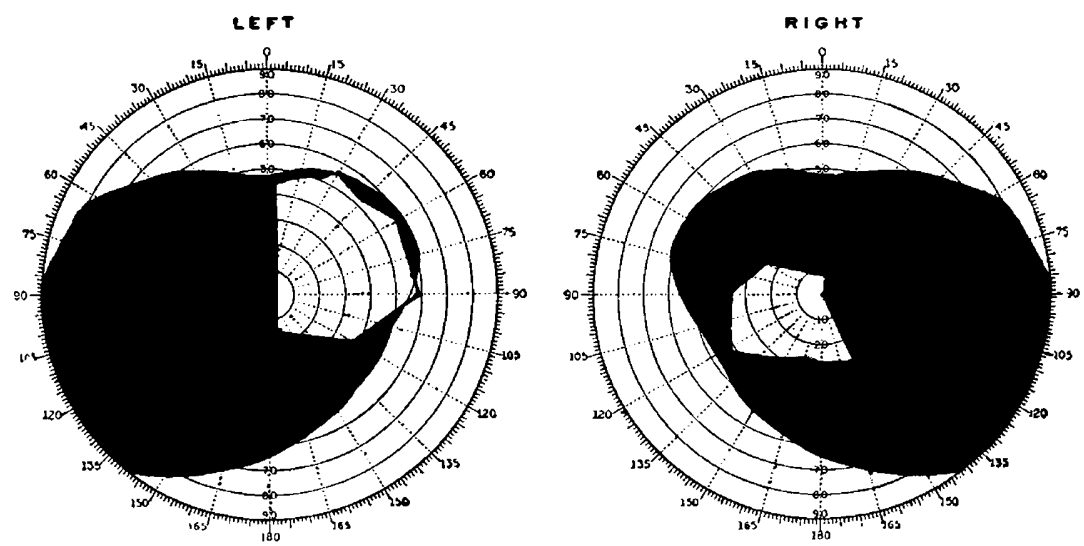

Fig. 8.-Visual fields for candle light in second case, showing the bitemporal hemianopsia.

headaches. These headaches often seemed to be precipitated by hard work, but they came at fairly regular intervals of one to two months. His habits had been good; he had used alcohol rarely and had not used tobacco, tea, or coffee. He had had occasional nocturnal emissions between the ages of 14 and 20 , but none since then. He had never married and had never had sexual intercourse.

The present trouble, in his opinion, dated back three or four years. During this time the headaches had increased greatly in severity, but the associated vomiting had lessened so that at the time of admission he rarely vomited. The headaches usually centered about the frontal region, extending down over the eyes. His sight began to fail about two years previously and the failure had gradually increased. He had become constipated, nervous, and inclined to isolation. Six years before he was advised to drink large quantities of water and he believed that in the last year he had been unusually thirsty. The patient left the hospital July 13, but returned Nov. 19, 1910, stating that his headaches had become more troublesome and that he had had some discomfort in the epigastrium without nausea or vomiting. His sight had fluctuated considerably, but had become worse on the whole. 
Examination.-Dec. 2, 1910, the patient appeared to be a short, slender and delicately proportioned man with a figure resembling that of a male adolescent (Figs. 5 and 6 ). Height in stocking-feet was 5 feet 2 inches, weighed 76 pounds. The head was well formed, the thoracic spine showed a slight kyphosis, the hands (Fig. 7) and feet were relatively long and slender. The skin over the face and hands was sallow, yellowish, dry and scaling; over the covered parts of the body it was soft and rather delicate. The cheeks and lips showed a few thin, colorless hairs; the hair over the body was fine and colorless; and there was almost an entile absence of axillary and pubie hairs. The penis appeared normal; the testicles were small and rather soft. The patient seemed nervous and emotional. The pupils were equal and reacted well to light and moderately well on acommotation, there being no paralysis of the extra-ocular muscles. The vision was so diminished that the patient could hardly count fingers. Oplithalmoscopic examination in the university eye clinie showed a primary-



Fig. 9.-X-ray plate of the base of the skull, Case 2, showing absence of normal outlines of sella turcica. The arrow points to the sella region and it is possible that the large pale area represents the abnormal sella (natural size).

optic atrophy. The visual fields, as determined by a lighted candle, showed a bitemporal hemianopsia (Fig. 8). The general strength was diminished but there was no definite paralysis and no disturbances of cutaneous sensation. The tendon reflexes were everywhere active, the skin reflexes not increased. The thyroid gland was neither seen nor felt. Lungs, heart, and abdomen were negative. A single blood-pressure determination on the first admission gave a systolic pressure of 110 , but on the second admission it was taken repeatedly and was constantly low, ranging from 84 to 87 . Wassermann reaction, gastric analyses, and microscopic stool examinations were negative. The urine, of which 1 to 2 liters were passed daily, showed a constantly low specific gravity, the average of twelve examinations being 1,006 , with 1,004 and 1,010 as extremes. A restriction of liquids for a week did not raise the specific gravity. Two 




lig. lo.--Anterior view of third patient showing small figure and wrinkled skill. 
radiographic plates (Fig. 9) taken transversely across the head showed an absence of the shadows normally cast by the bones surrounding the sella turcica. Plates of the hands, wrists, elbows and knees showed completed fusion of the epiphyses. The possibilities of operation were discussed with the patient but he declined on account of the danger and our inability to promise a restoration of sight.

CASE 3.-Retarded sexual development. Small frame. Large sella turcica.

History.-A man, aged $\tilde{5} 2$, came to the University Hospital at Ann Arbor April 24, 1911, complaining of stomach trouble. His family history was negative. He had four brothers, all of whom were of average height, ranging from 5 feet 7 inches to 5 feet 9 inches. The patient had never been very robust. Up to the age of 16 he had progressed normally in school but at that time he had an illness which was diagnosed as spinal meningitis and which interrupted his schooling. His first definite sexual feelings and first seminal emissions occurred at about the age of 30 years. This was followed by a period of masturbation, and since then by subnormal sexual impulses. The patient had never married and had never had sexual intercourse. He had always had more or less indi.

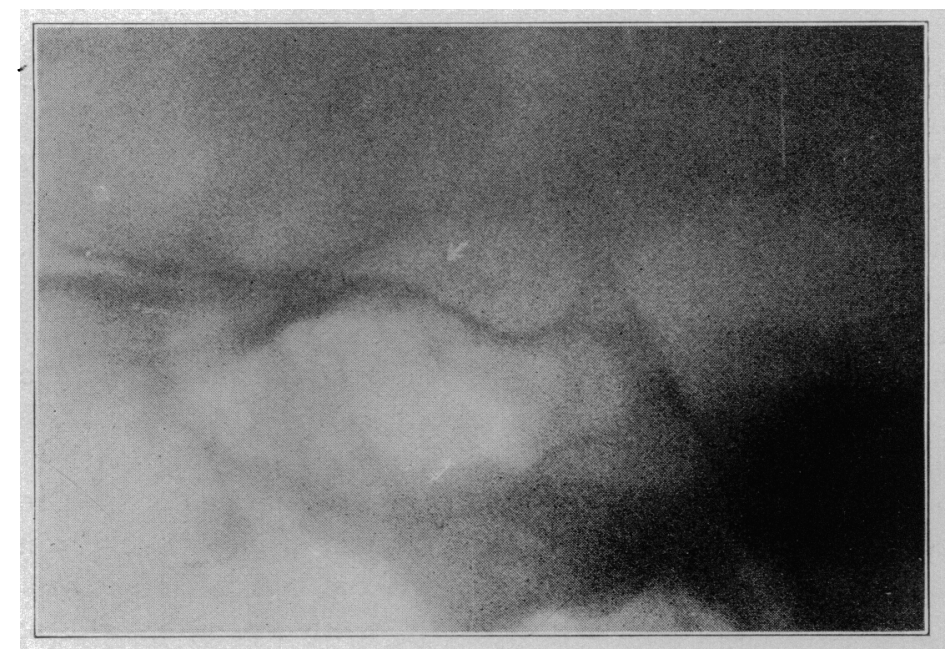

Fig. 11.-Skull of third patient, showing, enlargement of the sella turcica carity, with a wide entrance above (natural size). The arrow within the cavity points to the region of the tuberculum sellie. Ordinarily the shadow of the tubercle rises abruptly and joins that of the anterior clinoid process, giving a vertical shadow to the anterior wall of the cavity. Here, however, the flattening of the tubercle gives a pointed appearance to the anterior end of the cavity. The plate resembles that taken after death from the prepared skull of Erdheim's first patient, but in my case the sella is larger and the flattening of the tubercle more pronounced. (Erdheim, J.: Ueber Hypophysenganggeschwiilste und Hirncholesteatome. Sitzungsb. d. k. Akad. Wissensch. Math-naturw. Kl., 1904, cxiii, Part 3, p. 710.)

gestion with intestinal disturbances. He was in the hospital in 1906, at which time the diagnosis was made of neurasthenia, chronic gastritis, pigeon breast, and ulcerated septum. He entered again on account of epigastric distress after meals, belching of gas, and irregularity of bowels. Physical and laboratory examinations failed to show any definite organic cause for these complaints.

Examination.-The patient was a short man, 5 feet $2 \frac{1}{2}$ inches in his stockingfeet, weight $911 / 2$ pounds without clothes (Fig. 10). Like the preceding patient 
he was delicately built; the bones were small and slender; the hands relatively long and slender. The chest was rounded and was asymetrical, with a markedly protruding sternum. There was slight kyphosis in the upper thoracic spine. The skin of the face was deeply tanned and much wrinkled. The hands were cyanotic. The skin over the exposed parts of the body was dry and scaly; over the covered parts normal. The growth of hair was normal; the external genitalia rather small; knee-jerks were active; Wassermann reaction negative. The specific gravity of the urine was 1,012; quantity was not increased. Examination of the eyes in the eye department of the University Hospital showed a slight general limitation of the visual fields due to cortical cataracts. The optic nerves were rather pale, with arteriovenous compression. A radiograph of the skull showed a sella turcica somewhat larger than normal and characterized especially by an absence of the shadow of the tuberculum sellæ, and by a wide entrance from above into the fossa (Fig. 11).

We are indebted to the French school for numerous studies and discussions on the nature of infantilism. Various definitions for the condition have been proposed. Some would limit it to the persistence of childish or infantile characteristics in older people, while others prefer the more general conception of a "persistence in a given person of characteristics, bodily and mental, which belong to one of less advanced age." The Brissaud type of infantilism in which the characteristics of infancy or early childhood are especially retained is described as follows: "Round, chubby face, lips projecting and plump, small nose, smooth face, fine clear skin, fine hair, eyebrows and eyelashes scant, eyes prominent, large round cheeks, infantile face and head, skeleton under-developed, neck short and chubby, body long and cylindrical, abdomen prominent, limbs round and large, layer of fat over the whole body, infantile pelvis, lumbar lordosis, rudimentary sexual organs, no hair except on head, high-pitched voice, thyroid small, mind slow, retardation of ossification, absence or retardation of second dentition." My first patient showed many points in common with this description of the Brissaud type of infantilisyn. ${ }^{5}$ In him development had been arrested early in life and he showed many of the bodily, mental and sexual characteristics of childhood. Brissaud would attribute such arrested development to an insufficient thyroid secretion, but it seems certain that this conception is too restricted and that other causes may be operative. So far as hypopituitarism is concerned it is possible, of course, that this may influence the thyroid secretion or that it may be secondary to a thyroid disease, for the two glands bear an intimate relation to each other. According to Frankl-Hochwart, however, constant anatomic changes have not been demonstrated in the thyroids of patients with this type of pituitary disease, and the unusual intelligence of the first patient would speak against a marked thyroid insufficiency in his case.

The bodily development of the second patient differed from that of the first chiefly in the absence of obesity and in the general appearance

5. Brissaud: L’infantilisme vrai, Nouv. iconog. de la Salpêtrière, 1907, xx. 
of adolescence rather than of childhood. The infantilism in this case bore a general resemblance to that which usually goes under the name of the Lorain type, and has been described as follows: "Small stature, delicately-formed, slender skeleton, skin soft and pale, large shoulders, lower extremities long and slender, trunk relatively small, infantile sternum and pelvis, epiphyses normally united, no fat, abdomen normal, finely chiseled face, voice high, neck long, genital atrophy, absence of or slight secondary sexual characteristics." It has been claimed that these iwo types of infantilism are essentially different and that in the Brissaud, the fusion of the epiphyses is delayed, while in the Lorain type the fusion occurs at the normal time or prematurely. The value of this criterion has been shaken by the fact that in some cases of the Lorain type epiphyseal fusion has been retarded. ${ }^{6}$ It would seem that the two are not essentially different but that in the Brissaud type development is arrested at an earlier stage than in the Lorain type, due either to an earlier onset or to a more severe causative agency.

The Lorain type of infantilism appears to be rather unusual in pituitary disease, possibly on account of the frequent development of obesity which would mask its characteristic features. However, in one of Levi's ${ }^{6}$ patients and in that described by Lemann and Van Wart, ${ }^{6}$ typical Lorain infantilism was associated with presumable disease of the pituitary gland. It is important to note this oceurrence because it serves to indicate that the same group of causes may give rise to the different types of infantilism. Frankl-Hochwart believes that when pituitary disease occurs in early life obesity is more common than when it begins later, but this rule is subject to numerous exceptions. In my second patient a mild type of hypopituitarism occurring just before adolescence was probably sufficient to stunt the growth and to retard sexual development without inducing obesity. In the third patient the diagnosis is not well estalslished, but the enlargement of the sella turcica and the general resemblance to the second patient suggest that we ale dealing here with a mild form of hypopituitarism.

The first patient showed a typical diabetes insipidus, with very large quantities of urine and a constantly low specific gravity. Frankl-Hochwat found this condition mentioned in 7 fer cent. of the cases which he investigated. On the other hand, diabetes mellitus was very rare in his series, much more so than among the collected cases of acromegaly.

We are quite ignorant as to the precise nature of the diabetes insipidus which occurs in pituitary disease. It has been shown that the posterior

6. Levi, E.: Contribution a l'etude de linfantilisme de type Lorain, Nouv. iconog. de la Salpêtrière, 1908, xxi, 297. Lemann, Isaac I., and Van Wart, Roy M.: A Case of Infantilism with Absence of Thyroid and Tumor of Pituitary, The ARClives Int. Med., 1910, v. j̄19. 
and middle lobes of the gland may increase the flow of urine, and it is possible that an overaction of this portion of the gland may be associated with a diminished activity of the anterior lobe. Possibly, however, the diabetes insipidus results from nervous impulses excited by an irritation of structures at the base of the brain. In my second case, the urine was not increased markedly in amount, varying between 1 and 2 liters per day during his stay in the hospital. The examinations, however, were interesting in that they showed a constantly low specific gravity which areraged 1,006 and never exceeded 1,010. E. Meyer ${ }^{8}$ has shown that in true diabetes insipidus the kidney is unable to secrete concentrated urine, and I found that even though this patient took less than 500 c.c. of liquid per day, the specific gravity of his urine was not raised. Unfortunately it was not possible to make an accurate metabolic study.

\section{CONCLUSIONS}

1. The infantilism associated with disease in or near the pituitary gland may resmble either the Brissaud or the I.orain type of infantilism.

2. A constantly low specific gavity of the urine in patients with such disease may be the equivalent of a mild diabetes insipidus.

902 Baldwin Avenue.

7. Schifer: 'lite Functions of the Pituitary Borly, l'roc. Roy. Soc. Biol., lxxxi, $4+2$.

8. Meyer, E.: Lober Dialictes insijuidts und andere Polyurien, Deutsch. Areh f. klin. IIed., 1904, Ixxxiii, 1. 